
\title{
is Research Suare \\ On the population density limit to variable renewable energy potential
}

Gil Barnea ( $\sim$ gilbarnea@mail.tau.ac.il )

Tel-Aviv University

Nir Barnea

The Hebrew University

\section{Research Article}

Keywords: Renewable energy density, population density, land footprint, installed capacity

Posted Date: February 15th, 2021

DOl: https://doi.org/10.21203/rs.3.rs-239062/v1

License: (9) This work is licensed under a Creative Commons Attribution 4.0 International License. Read Full License 


\title{
Journal Name
}

\section{ARTICLE TYPE}

Cite this: DOI: $00.0000 / x x x x x x x x x x$

\section{On the population density limit to variable renewable energy potential}

\author{
Gil Barnea ${ }^{a}$ and Nir Barnea ${ }^{b}$
}

Received Date

Accepted Date

DOI: $00.0000 / x x x x x x x x x x$

Renewable energies are expanding rapidly around the globe. In several countries, however, their expansion is being challenged by NIMBY groups and land footprint. In this article, we suggest that indeed a major challenge for renewable energy expansion appears to be tied to land use questions, especially in regions with high population density. Our research finds a strong relationship between population density and renewable energy expansion. The power density of Variable Renewable Energy (VRE) sources, such as wind turbines or photovoltaic panels, is much lower than that of fossil fuels or nuclear power plants, to the extent that land availability seems to be the limiting factor for large scale VRE production. During the last decade, a substantial theoretical effort was dedicated to study the actual power density of VRE, and the available space in order to estimate the limits that land footprint sets on VRE production. On top of the technological, and geographical issues associated with such studies there are somewhat more complicated and less well defined sociological issues related to the willingness of population to live in near proximity to large scale VRE farms. To explore the overall issue of VRE penetration and limitations, the installed VRE capacity data from different countries is examined. It is found that in Germany, with VRE power density of 0.27 $\mathrm{W} / \mathrm{m}^{2}$ (2018 data), there is a strong negative correlation between the population density and VRE capacity, dominated by solar power production. We interpret this correlation as an indication that Germany has reached the point where land usage is becoming the limiting factor for installation of new VRE power plants. As Germany is a worldwide leader in VRE production per capita with more than $1 \mathrm{~kW} /$ person, we speculate that this sets a universal barrier of $2 \%-3 \%$ on the fractional land area available for VRE production. Crossing this barrier the expansion of the installed VRE capacity is expected to stall. This does not, however, mean that renewable energy expansion will be doomed in countries with high population density. Rather it suggests the need for new approaches a stronger focus on battery storage technologies, inter-sectoral coupling (renewable energy storage in automobile batteries) and continued investment in efficiency improvements of renewable energy technologies. It may also be a question of how renewable energy develops - enhancing solar on existing built infrastructure (rooftops, siding, and even roads) could help address this issue.

\section{Introduction}

The current quest for sustainable energy sources relies to large extent on energy production from wind and solar power plants (VRE). The U.S. Energy Information Administration (EIA) estimates (2019 Outlook) that the world energy consumption will grow by nearly 50\% between 2018 and 2050.1 About 70\% of this growth is expected to come from wind and solar sources in countries that are not in the OECD. The production of electricity using these renewable technologies involves larger acreage than more traditional energy sources. This issue has long been a source of criticism, questioning the feasibility of large scale

\footnotetext{
a Boris Mints Institute for Strategic Policy, Tel Aviv University, Tel Aviv 69978, Israel.

${ }^{b}$ The Racah Institute of Physics, The Hebrew University, Jerusalem 91904, Israel.
}

VRE implementation. The literature analyzing the transition to a $100 \%$ renewable energy production (mostly wind, water and sun) at the local ${ }^{2[5}$ or global ${ }^{6}[8]$ level use either a bottom-up approach and/or theoretical modeling. ${ }^{9}$ Some works conclude that land use will not pose a significant constraint on the transition to renewables, $10[11$ others claim the opposite, predicting that land footprint will be a major obstacle for large scale renewable energy penetration. 12 -14 One major reason for the wide range of results is the uncertainty in the power density, and the environmental and sociological effects of wind and solar energy projects. $.915,16$ Therefore, the question as to what is the maximal feasible amount of installed VRE capacity, has been at the focus of renewable energy debate in the last decades. Much effort has been dedicated to analyze the different aspects of large scale VRE production, being technical, sociological, agricultural, or financial. 12|13|17|22 
The power density, measured in energy production rate of Watts (W) to unit area of $\mathrm{m}^{2}$, varies dramatically between different energy sources. ${ }^{12}$ The estimated values for nuclear (1000 $\left.\mathrm{W} / \mathrm{m}^{2}\right)$, coal $\left(100-1000 \mathrm{~W} / \mathrm{m}^{2}\right)$, and gas $\left(4000-5000 \mathrm{~W} / \mathrm{m}^{2}\right)$ power plants indicate that they are the most efficient by this metric, disregarding extraction and transportation land use.12 14 On the other hand, biofuels such as ethanol production from corn (0.3-0.36 W/ $\left.\mathrm{m}^{2}\right)$, and biomass burning $\left(0.17-2.7 \mathrm{~W} / \mathrm{m}^{2}\right)$ are the most wasteful in land use per unit power. VRE production from wind turbines (1.6-2.5 W/ $\mathrm{m}^{2}$ ) and solar photovoltaic (PV) panels (2.5-6 W/ $\left.\mathrm{m}^{2}\right)$, have intermediate values on this metric. It should be noted, however, that these estimates can vary dramatically de-

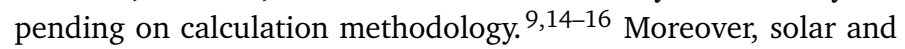
wind power generating facilities can have multi-purpose land use. Many onshore wind farms are placed in cultivated agricultural areas, PV panels can be mounted on rooftops, and the land under PV power plants can be used for water reservoirs, crop production, and food security. $6|10| 18 \mid 23$ Wind farms deliver about 2.5 $\mathrm{W} / \mathrm{m}^{2}$, PV farms in Bavaria, Germany, and Vermont, USA, deliver $4 \mathrm{~W} / \mathrm{m}^{2}$, and the average power production using solar technologies is $3-20 \mathrm{~W} / \mathrm{m}^{2}$, depending on the area (sunny/cloudy/desert area) and method (PV panels, or concentrated solar energy). 20 Wind and solar farms in the United States have been found to deliver similar output at $0.5 \mathrm{~W} / \mathrm{m}^{2}$ and $5.4 \mathrm{~W} / \mathrm{m}^{2}$, respectively. 9

The world's average power consumption is about $0.1 \mathrm{~W} / \mathrm{m}^{2}$ per person, but about $78 \%$ of the world's population lives in countries that have power consumption per unit area larger than 0.1 $\mathrm{W} / \mathrm{m}^{2}$. Large and less populated countries such as Russia, Canada and Australia which have high energy consumption per capita are under $0.01 \mathrm{~W} / \mathrm{m}^{2}$ unit area. The US, China, and India have average consumption per capita above $0.1 \mathrm{~W} / \mathrm{m}^{2}$, while the $\mathrm{UK}$, and Germany have an energy consumption per capita above $1 \mathrm{~W} / \mathrm{m}^{2}$. Comparing the power consumption density to the power production density of VRE it is evident that they are uncomfortably close for the latters, if we are to think of VRE as the only available energy sources. His conclusion was that for Britain to have renewables providing $100 \%$ of its power consumption, the British island should be covered by PV panels and wind turbines. 20

As the land footprint is arguably the most important limitation on large scale VRE installation, and in view of its ever increasing penetration, the question we would like to address here is whether one can already observe the impact of land use on the development of wind and solar farms.Surprisingly, the answer to this question is positive. Exploring the level of energy production from solar and wind sources in crowded states and provinces and in sparsely populated areas, in this study we examine the relation, on the states level, between the population density and installed VRE capacity per person in the USA, India, China, and Germany. Countries that are dominating forces in the VRE arena. ${ }^{24}$ Doing so, it is found that for Germany, the world leader in renewable energy penetration with installed VRE power density capacity of $0.27 \mathrm{~W} / \mathrm{m}^{2}$, equivalent to $40 \%$ of the country's electricity production in 2018, there is a very strong negative correlation between the two. ${ }^{25}$ The same correlation albeit much weaker appears also for China. Such strong correlation suggests that land usage is becoming the key factor for further development of VRE in Ger- many. We conjecture that this indicator sets the upper limit for VRE production worldwide. For the USA, India, and the rest of the world which is lagging far behind Germany in the level of installed VRE capacity, this boundary has not been reached yet.

Following this introduction, the theoretical model is presented in section 2, relating the VRE production per capita to the population density. The data base used in this work is presented in section 3, and its analysis in section 4, Sections 5, and 6 discuss the possible implications and the conclusions of the current work.

\section{Theoretical Model}

To establish the connection between renewable energy and population density, consider a hypothetical group of states, or provinces, that have the same regulatory system, culture, natural conditions, and admixture of wind and solar farms, and that the only difference between them is their population density. This hypothetical situation can be regarded as an idealized picture of large countries, such as the USA or China, which are either a federation of states or are composed of sizable provinces.

The installed VRE capacity, i.e. the total VRE power $Q_{r e}$, in these states is equal to the land dedicated to VRE production $A_{r e}$ times the VRE power density $w$,

$$
Q_{r e}=w A_{r e}
$$

The area $A_{r e}$ includes the acreage of, e.g., wind power facilities, PV rooftop installations, and solar energy farms. The power density $w$ depends on the geographical conditions, such as latitude and climate, 6 and on the details of installed facilities, however as the power density of wind turbines and PV panels is rather similar, 14 the assumption that $w$ is a constant independent of the specific state seems to be a reasonable assumption, within a factor of 2 or so, also in reality. The second model assumption is that the amount of land the people in each of these states are willing to dedicate to VRE production is a constant fraction $\alpha$ of the total area of the state $A$, i.e. $A_{r e}=\alpha A$. It follows that the total amount of VRE power in a state is proportional to its area,

$$
Q_{r e}=\alpha w A .
$$

Dividing both sides of this equation by the state's population $N$, noting that $n=N / A$ is the population density, defining $q_{r e}=Q_{r e} / N$ to be the installed VRE capacity per person, and $b_{c}=\alpha w$ to be the effective power density, one gets the relation

$$
q_{r e}=\frac{b_{c}}{n},
$$

i.e. the installed VRE capacity per capita is expected to be inversely proportional to the population density. As the land fraction dedicated to VRE $\alpha$, and the VRE power density $w$ are assumed to be the same for all the states/provinces in the theoretical ensemble, it follows that $b_{c}$ is a constant independent of the specific state that is common to the whole group of states, i.e. country-hence the subscript ' $c$ '.

Taking now the logarithem of both sides one gets the linear relation

$$
\log \left(q_{r e}\right)=\log \left(b_{c}\right)-\log (n)
$$


This model is expected to hold when $q_{r e}$ is dominated by the land availability, at this point one would expect to see the linear correlation (4) with slope of -1 between the logarithems of the installed VRE capacity per person in each state and its population density.

To conclude this section, it is interesting to compare the VRE production model presented above, Eq. (3), with a competing theoretical model where the electric energy production per person $q_{p}$ is dominated by the power demand. Considering again a group of states/provinces with equal status of leaving and development level, and assuming that the size of these entities is large so that they rely on local electricity production, in the latter case we expect that $q_{p}=$ Constant. This model is very different from Eq. (3), and as we shall see it is refuted by the installed VRE capacity data.

\section{Data}

As discussed earlier, the level of energy production from solar and wind sources in different countries depends not only on its power density but on many other factors such as geography, regulations, wealth, or culture. To reduce the variance in this study and to get a sample of states closer to the hypothetical model, we first study the impact of density on VRE penetration across different provinces or states belonging to the same sovereign country. Focusing on China, India, Germany, and the USA. According to the Renewable Energy Country Attractiveness Index (RECAI) published by Ernst \& Young, these 4 countries are among the most attractive countries for renewable investments. 26 The International Energy Agency predicts that China, the USA, and India will account for two thirds of the global renewable expansion by 2022 . China made a substantial progress during the last two decades and gave access to electricity to most of the population in urban and rural areas. $\frac{24}{24}$ India is still considered as the world's largest country with electricity access deficit, with large popu-

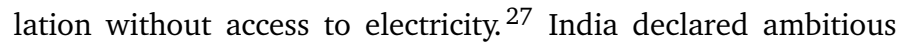
goals for VRE implementation, assuming potential of $3 \%$ of the country's wasteland is available for solar power. ${ }^{28 \mid 29}$ On the other hand, Germany \& the USA are the leading countries in the OECD with strong economy and electricity sector. Germany is the world leading country regarding the phaseout of nuclear energy and the adoption of "green"-renewable energy based-agenda. $\stackrel{30}{\text { Later }}$ analysis of the World Wildlife Fund (WWF) assumes that Germany could achieve $100 \%$ renewables using $2.5 \%$ of its land and massive offshore wind turbines. $\frac{31}{1 n}$ In 2005 , the US National Renewable Energy Laboratory (NREL) estimated that solar energy can provide $100 \%$ of the USA electricity needs while using about $0.6 \%$ of the country's total land area. ${ }^{32}$ In 2013 the NREL published a new report based on the accumulated data from the existing solar projects, rejecting the former estimates due to the high variance between different projects. ${ }^{33}$ Their conclusion was that solar energy footprint should be recalculated in the future based on real data.

As of 2015, the total installed electricity capacity per person (p) in India was $0.26 \mathrm{~kW} / \mathrm{p}$, in Germany $2.49 \mathrm{~kW} / \mathrm{p}$, in the USA 3.31 $\mathrm{kW} / \mathrm{p}$, and in China $1.11 \mathrm{~kW} / \mathrm{p}$. The population density of these countries is $n \approx 460 \mathrm{p} / \mathrm{km}^{2}$ in India, $n \approx 240 \mathrm{p} / \mathrm{km}^{2}$ in Germany, $n \approx 152 \mathrm{p} / \mathrm{km}^{2}$ in China, and $n \approx 36 \mathrm{p} / \mathrm{km}^{2}$ in the USA. ${ }^{34}$ For these big countries, the density in each state/province is much different than the average density on the country level, so they provide an important test ground for the theoretical model.

After analyzing the data for these 4 countries we study the implications of the results on 131 countries worldwide. The data for these countries is taken from REN21, the German renewable energy agency, and the EIA. 35.37

It should be noted that when analyzing the VRE data of Germany, USA, China and India offshore wind installations are disregarded. Only solar and onshore wind installations are considered.

\section{Analysis}

We start the analysis examining the relation (4) between the logarithems of the VRE capacity and the population density. Fig. 1 presents, on a logarithmic scale, the installed VRE per person versus the population density for Germany (2015). The plotted blue line represents a fitted value of $b_{c}=0.23 \mathrm{~W} / \mathrm{m}^{2}$, and the dots the different states. On the lower right end of the figure, one finds the city states of Berlin and Hamburg, with high population density and smaller amount of VRE capacity, while on the upper left end one finds the least populated states of former Eastern Germany that are leaders in renewable electricity production, having enough space for constructing solar and wind power plants. 38 From the figure one can clearly see the strong correlation between the population density and the VRE capacity per capita. To quantify this observation we have calculated the Pearson correlation coefficient $r$ between the two for all the states/provinces in China, India, Germany, and the USA, including the city states such as Bremen, Berlin, and Hamburg in Germany, and the District of Columbia in the USA. The results, presented in Table 1 show that for Germany, having the largest VRE penetration level, the Pearson correlation is very close to -1 . This indicates that Germany has arrived to the VRE saturation line where land availability is becoming the single most important factor influencing the development of the renewable energy market. China and the USA exhibits a similar trend, albeit much weaker. India, on the other hand, displays an opposite behavior, i.e. positive correlation. Similar results are obtained when repeating the calculations using the Spearman correlation analysis. More advanced statistical tools can also be used to analyze the data, $\underline{39140}$ however they should not change the conclusions.

Table 1 The Pearson correlation $r$ between the installed VRE capacity and the population density. The second column presents the VRE percentage of total electricity production capacity. The third column is $r$ calculated for all states belonging to the country. The last two columns present $r$ for the states with installed VRE capacity per unit area $q_{r e} n$ greater than $10^{-3} \mathrm{~W} / \mathrm{m}^{2}$, and $10^{-2} \mathrm{~W} / \mathrm{m}^{2}$ respectively.

\begin{tabular}{ccccc}
\hline Country & $\% \mathrm{VRE}$ & All states & $10^{-3} \mathrm{~W} / \mathrm{m}^{2}$ & $10^{-2} \mathrm{~W} / \mathrm{m}^{2}$ \\
\hline India & $9 \%$ & +0.25 & -0.76 & -0.74 \\
USA & $9 \%$ & -0.39 & -0.66 & -0.85 \\
China & $11 \%$ & -0.64 & -0.78 & -0.88 \\
Germany & $41 \%$ & -0.95 & -0.95 & -0.95
\end{tabular}

The VRE power density for the different German states varies between $0.1-0.4 \mathrm{~W} / \mathrm{m}^{2}$. It is much larger and uniform than in the 


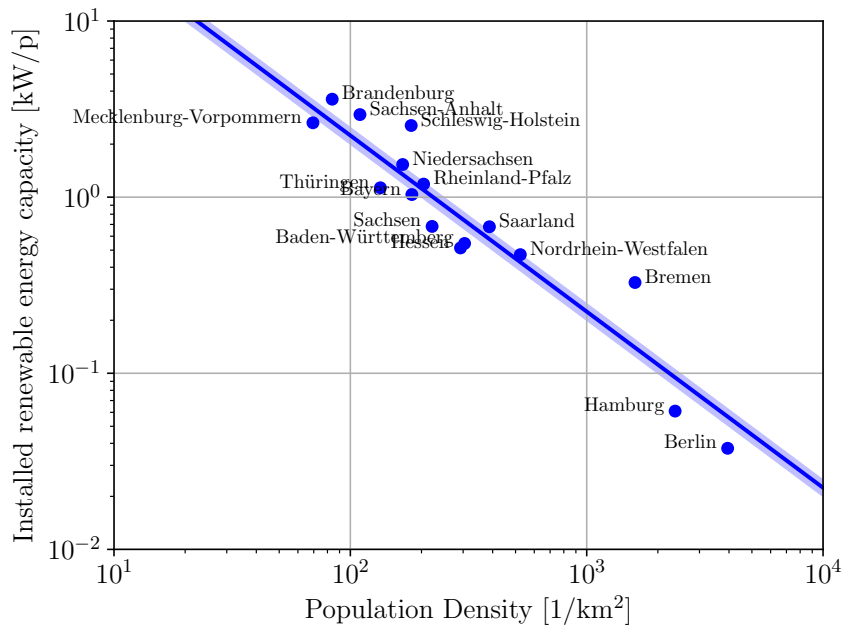

Fig. 1 Installed VRE capacity per capita vs the population density, in the different German states (2015). The blue line results from (3) with the best estimate for $b$, the light blue band stands for an error of \pm standard deviation in $b$. Data source: Germany Renewable Energies Agency.

other countries, e.g. for India is varies between $10^{-6} \mathrm{~W} / \mathrm{m}^{2}$ and $0.1 \mathrm{~W} / \mathrm{m}^{2}$. We expect land availability to dominate VRE penetration when the dedicated areas become substantial. In order to test this hypothesis we should consider only those states that have average VRE power density larger than some cutoff. For example, in Fig. 2 the grey dashed line is used to separate the Chinese provinces with $q_{r e} n \geq 10^{-2} \mathrm{~W} / \mathrm{m}^{2}$, given by bold red dots, and those with smaller VRE penetration, given by pale red dots. From the figure it can be seen that the provinces with the higher VRE power density tend to cluster around the model, given by the red line with fitted value of $b_{c}=0.027 \pm 0.004 \mathrm{~W} / \mathrm{m}^{2}$, whereas the other provinces show no such correlation. Following this example, Table 1 presents the calculated Pearson correlations for all 4 countries considering now only those states with $q_{r e} n \geq 10^{-3} \mathrm{~W} / \mathrm{m}^{2}$, and $q_{r e} n \geq 10^{-2} \mathrm{~W} / \mathrm{m}^{2}$. From the table it is evident that, as expected, the correlation increases with the cutoff (except for one case in India). Indicating thatland availability becomes an issue already at average installed VRE power density of $10^{-3}-10^{-2} \mathrm{~W} / \mathrm{m}^{2}$.

To check the validity of the model a slope different from -1 in Eq. (4) was allowed. Doing so, it was found that for Germany (2015) the calculated slope was $-1.05 \pm 0.09(1 \sigma)$. Looking also separately at the solar and wind components of the German VRE capacity it was found that for solar $r=-0.97$ and for wind $r=$ -0.85 . Pointing that the VRE saturation effect is dominated by installation of solar farms. This might not be that surprising as in contrast with large scale PV installations, wind mills allow for a dual land use.

This last point can be reinforced analyzing the time evolution of the installed VRE capacity. Between 2001 and 2018 the amount of installed VRE power in Germany has increased from 8.8 GW to $97.8 \mathrm{GW}$, a growth of more than $1000 \% .25$ Over this period the total VRE power density parameter $b_{c}$ changed from $b_{c}=0.017 \pm 0.004 \mathrm{~W} / \mathrm{m}^{2}$ (2001) to $b_{c}=0.27 \pm 0.03 \mathrm{~W} / \mathrm{m}^{2}$

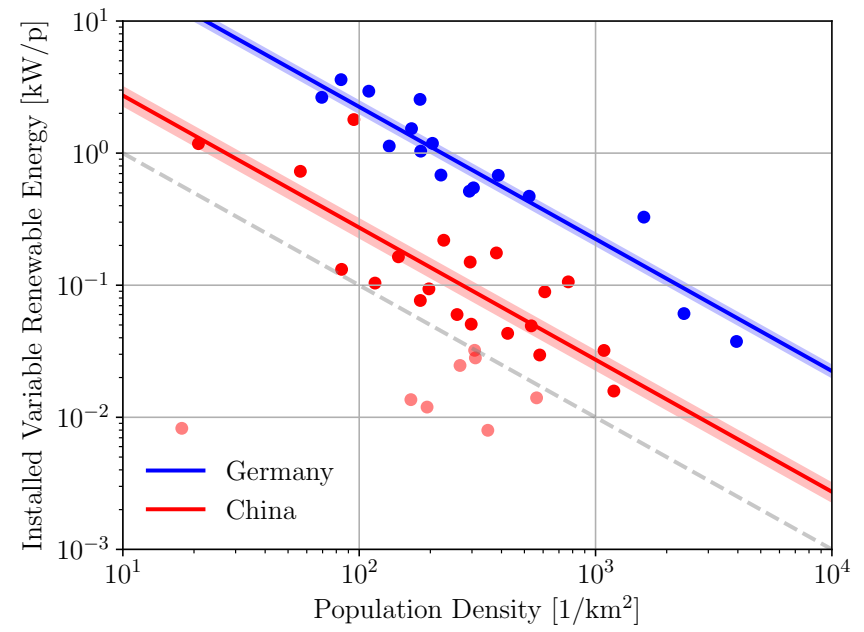

Fig. 2 Germany and China states Installed VRE capacity per capita vs the population density (2015). The blue dots are Germany's states and the blue line shows Germany's $0.23 \pm 0.02 \mathrm{~W} / \mathrm{m}^{2}$ fit. The red dots are China's states and the red line shows China's $0.027 \pm 0.004 \mathrm{~W} / \mathrm{m}^{2}$ gradient. The light gray band stands for the cutoff of $0.001 \mathrm{~W} / \mathrm{m}^{2}$ for states with low power density.

(2018), while the corresponding Pearson correlation changed from $r=-0.79$ to $r=-0.95$. The change in $|r|$, and $b_{c}$ over this period for the wind and solar components of the German VRE capacity is presented in Fig. 3. Inspecting the figure it can be seen that for wind both $b_{c}$, and $|r|$ grow more or less in a linear manner from 2001 to 2018, with $r$ changing in a moderate way from $r=-0.65$ (2001) to $r=-0.85$ (2018). In contrast, for the solar installations one can observe two distinct periods. Up to 2012 the solar VRE capacity is characterized by a linear growth in $|r|$ and an exponential growth in $b_{c}$. In 2012 the Pearson correlations hits the value of $r=-0.96$ and stalls, and $b_{c}$ goes through a dramatic transition as its the growth pattern change from exponential to linear. Furthermore, in this year, the rate of new PV installations dropped from its peak of about $8000 \mathrm{MW} /$ year to the current rate of 2000-3000 MW/year, 36 even while solar panel prices continued to drop down rapidly. 41

This transition indicates the onset of a saturation effect in the installed solar VRE capacity. The power density parameter $b_{c}$ for the solar installations at the 2012 transition point is $b_{c}=$ $0.075 \pm 0.007 \mathrm{~W} / \mathrm{m}^{2}$. Assuming these installations to be PV panels, and comparing $b_{c}$ with the power density $w \approx 2.5-4 \mathrm{~W} / \mathrm{m}^{2}$ of PV panels,, 20 one can estimate that when the land fraction $\alpha$ reaches the value $\alpha \approx 1.8 \%-3.0 \%$ solar energy saturation happens.

Using the available data at this point we cannot predict a limiting value of $b_{c}$, yet in view of the available data one can deduce that with the current technology land availability is the limiting factor for further solar VRE growth in Germany, and that increasing $b_{c}$ by a factor of 2-3 would not be easy.

\section{Discussion}

In view of Germany's leadership in renewable energy production, the strong negative correlation found between its population den- 

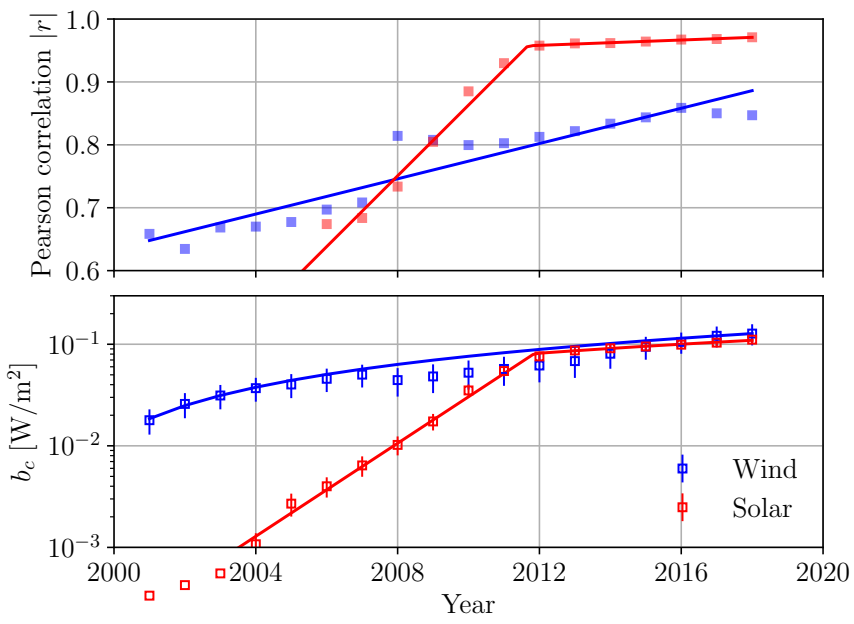

Fig. 3 The correlation between installed VRE capacity per capita and the population density in Germany as a function of time. Top: The absolute value of the Pearson correlation $|r|$. Bottom: The power density parameter $b_{c}$. Blue squares: onshore wind. Red squares: solar. The lines are linear or exponential fits to the data.

sity and installed VRE capacity suggests that the relation (3) with $b_{c}=0.27 \mathrm{~W} / \mathrm{m}^{2}$, may provide an upper bound to VRE power density worldwide. To examine this point, Fig. 4 presents the population density versus VRE data for 131 countries (some are cut out). In this figure it can be seen that indeed at this stage no country is crossing the German $b_{c}=0.27 \mathrm{~W} / \mathrm{m}^{2}$ line. The countries closest to the line, as of 2015, are Belgium with power density of 0.174 $\mathrm{W} / \mathrm{m}^{2}$, Denmark with $0.137 \mathrm{~W} / \mathrm{m}^{2}$, and Italy, Japan and UK with around $0.1 \mathrm{~W} / \mathrm{m}^{2}$. The rest of the world is lagging far behind.

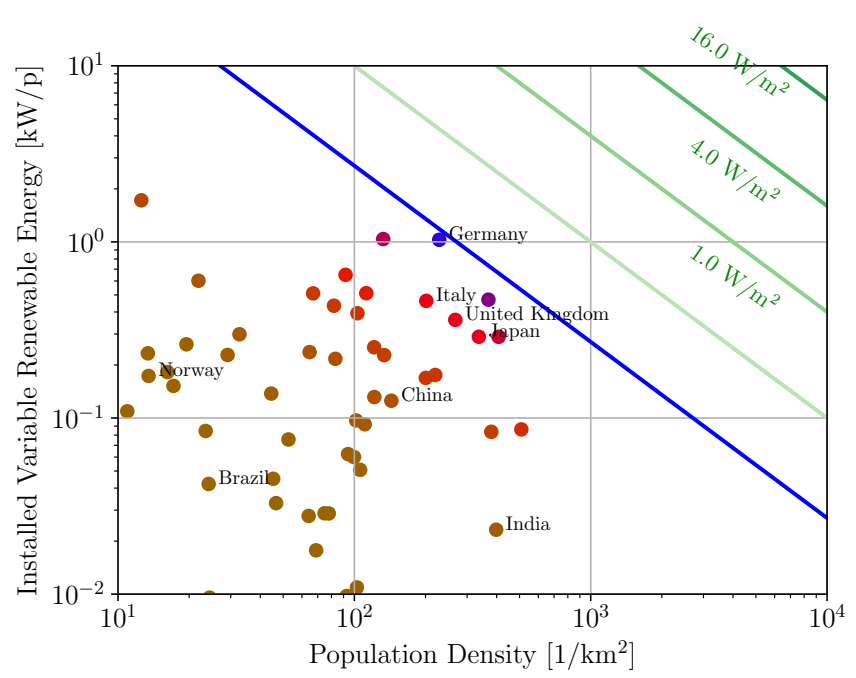

Fig. 4 Installed VRE and population density for 131 countries worldwide (2015 data).35 The blue trend line represents Germany's (2018) 0.27 $\mathrm{W} / \mathrm{m}^{2}$ fit. The green lines represent theoretical solar and wind density calculated theoretical limits of $1.0,4.0,16.0 \mathrm{~W} / \mathrm{m}^{2}$.

Using the German line as a reference point it is interesting to check now which countries can rely on VRE to account for their total electricity consumption, ignoring for the sake of discussion important issue such as storage, geographical, and seasonal variations. In Fig. 5 the electricity production capacity per person for each country is plotted versus its population density, in comparison with the $b_{c}=0.27 \mathrm{~W} / \mathrm{m}^{2}$ line. Inspecting the figure it can be seen that only 22 countries (the red ones above the black trend line) out of the 131 examined in this work had total electricity density greater than $0.27 \mathrm{~W} / \mathrm{m}^{2}$. Most of these are rich and highly populated European countries (Austria, Belgium, Czech Republic, Denmark, Germany, Malta, Italy, Luxembourg, Netherlands, Switzerland, United Kingdom), some are islands (Bahrain, Barbados, Japan, Maldives, Mauritius, Singapore, Trinidad and Tobago), and the rest are Israel, South Korea, Kuwait, and the United Arab Emirates. In reference to 2050 projections, forecasting a fast increase in VRE installations in developing and developed countries alike, ${ }^{1}$ we can assume that countries with high population density (above $100 \mathrm{p} / \mathrm{km}^{2}$ ) and low energy consumption (less than $1 \mathrm{~W} / \mathrm{m}^{2}$ )-i.e. the green dots in the low right side of Fig. 5-will reach this barrier of land footprint in the coming decades.

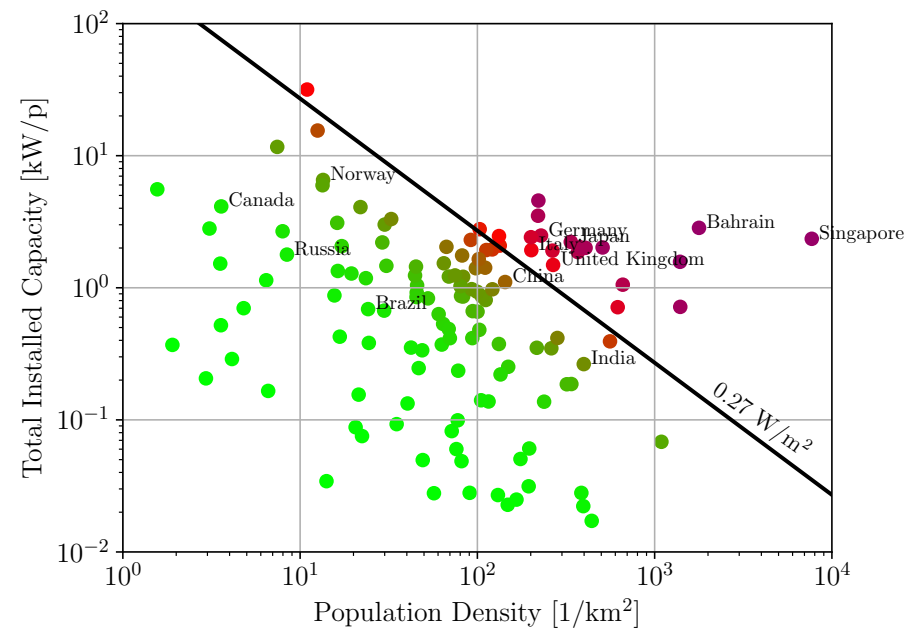

Fig. 5 The installed electricity production capacity and population density for 131 countries worldwide (2015 data). The black trend line represents Germany's $2018 b_{c}=0.27 \mathrm{~W} / \mathrm{m}^{2}$ value.

In order to rely on solar energy as their sole energy source, Germany, Malta, South Korea, Belgium, and some other countries would need to dedicate above $50 \%$ of their land to solar farms. Our findings indicate that such high coverage is highly improbable. 13

\section{Conclusions}

The transformation from fossil fuels to renewable energy is associated with large land appropriation. Land use aspects differ between countries and are influenced by a variety of factors such as economy, society, policy, culture, geography and more. $\frac{39 / 40}{.6}$ This study adopts an empirical approach to analyze the global effect of these factors, inspecting the relation between VRE production capacity and population density. The data examined in this paper includes (i) The installed solar and onshore wind power 
production capacity in Germany between 2001 and 2018, (ii) The installed solar and onshore wind power production capacity in China, India, and the USA at the state/province level (2015 data), and (iii) 131 countries worldwide at the country level (2015 data). We have found an emerging negative correlation between installed VRE capacity and population density, appearing already at relatively low VRE penetration levels of about 0.001 $\mathrm{W} / \mathrm{m}^{2}$, and getting stronger with increasing penetration. These findings sugget that the theoretical predictions that land availability and usage form a physical barrier to high VRE expansion in dense countries, has practically materialized. In this regard, the empirical results analyzed here support the findings of related work. 14$] 15 / 20$ In addition, these findings cast a new light regarding the importance of land footprint at relatively low level of VRE penetration, as it seems to be the decisive factor already at average installed VRE capacity of less than $0.3 \mathrm{~W} / \mathrm{m}^{2}$ corresponding to land coverage of order $1 \%$. Furthermore, even at lower levels of VRE penetration $\approx 0.03 \mathrm{~W} / \mathrm{m}^{2}$, as in parts of China, India or the US, VRE is strongly correlated to population density. In Germany, it seems that land availability becomes, de facto, the most important obstacle to further VRE growth, specially for solar power production. This barrier can be managed and pushed up through a change in the VRE solar and wind mixture, by adding offshore turbines, extensive storage technologies, inter-sectoral coupling and improvements efficiency of VRE technology, or through a change in policies, and regulations that limits, e.g., the distance of solar and wind farms from population.

Summing up, our results cast a new light on the actual relations between VRE expansion, population density and land use. The results found show an interesting picture from which one can deduce limits on VRE penetration in crowded provinces, open landscapes or populated urban areas.

Future investigations are necessary to further validate the conclusions drawn from this study. Enlarging and updating our data base, correcting for geography, and insulation can improve the robustness of the conclusions.

\section{Conflicts of interest}

There are no conflicts to declare.

\section{Acknowledgements}

We would like to thank Itai Sened, Miranda Schreurs and Stefan Wurster for their help preparing the renewable energy data base, and for useful discussions during the preparation of this work.

\section{Notes and references}

1 International Energy Outlook 2019, United States Energy Information Administration (EIA) technical report, 2019.

2 H. Lund and B. V. Mathiesen, Energy, 2009.

3 K. Hansen, B. V. Mathiesen and I. R. Skov, Renewable and Sustainable Energy Reviews, 2019, 102, 1-13.

4 R. Bramstoft and K. Skytte, International Journal of Sustainable Energy Planning and Management, 2017, 14, 3-20.

5 D. Connolly, H. Lund and B. V. Mathiesen, Smart Energy Europe: The technical and economic impact of one potential 100\% renewable energy scenario for the European Union, 2016.
6 E. Weiner, S. Redfern, S. C. Goodman, M. A. Sontag, P. Enevoldsen, J. Lo, I. Petkov, H. A. Clonts, K. R. Moy, J. R. Erwin, S. N. Fobi, W. E. Chapman, M. A. Delucchi, A. S. Yachanin, J. Liu, E. M. Hennessy, L. Chobadi, Z. A. Bauer, S. B. Morris, R. Schucker, M. A. Cameron, M. Z. Jacobson, C. B. Meyer, J. Wang, O. K. Goldstrom, P. L. O'Neill and C. Bozonnat, Joule, 2017, 1, 108-121.

7 M. Z. Jacobson, $100 \%$ renewable energy requires less land footprint than fossil fuels in California, 2018, http://redgreenandblue.org/2018/08/27/100renewable-energy-requires-less-land-footprintfossil-fuels-california/.

8 M. A. Delucchi and M. Z. Jacobson, Energy Policy, 2011, 39, 1170-1190.

9 L. M. Miller and D. W. Keith, Environmental Research Letters, 2018, 13, 104008.

10 M. Z. Jacobson and M. A. Delucchi, Energy Policy, 2011, 39, 1154-1169.

11 S. Singer, J.-P. Denruyter and D. Yener, The Energy Report: 100 \% Renewable Energy by 2050, 2017, pp. 379-383.

12 D. J. C. MacKay, Sustainable energy-without the hot air, UIT Cambridge Ltd., 2009.

13 I. Capellán-Pérez, C. de Castro and I. Arto, Assessing vulnerabilities and limits in the transition to renewable energies: Land requirements under 100\% solar energy scenarios, 2017, https://www.sciencedirect.com/science/ article/pii/S1364032117304720.

14 V. Smil, Power Density Primer: Understanding the Spatial Dimension of the Unfolding Transition to Renewable Electricity Generation ( Part I - Definitions ), 2010, https://www.masterresource.org/smil-vaclav/smildensity-definitions-i/

15 C. de Castro, M. Mediavilla, L. J. Miguel and F. Frechoso, Renewable and Sustainable Energy Reviews, 2013, 28, 824-835.

16 C. de Castro, M. Mediavilla, L. J. Miguel and F. Frechoso, Energy Policy, 2011, 39, 6677-6682.

17 R. Bryce, The Real Problem With Renewables, 2010, https: //www.forbes.com/\#60acf 2851403

18 P. Denholm and R. M. Margolis, Energy Policy, 2008, 36, 3531-3543.

19 Proceedings of the 2012 Land Policy Conference, 2013.

20 D. J. C. MacKay, Philosophical transactions. Series A, Mathematical, physical, and engineering sciences, 2013, 371, 20110431.

21 R. I. McDonald, J. Fargione, J. Kiesecker, W. M. Miller and J. Powell, PLoS ONE, 2009, 4, e6802.

22 G. Walker, Land Use Policy, 1995, 12, 3-6.

23 S. Roy and B. Ghosh, Renewable Energy, 2017, 114, 12381246.

24 Renewables 2017: Analysis and forecasts to 2022, International Energy Agency (IEA) technical report, 2017.

25 Renewable Shares, 2019, https://www . energy-charts.de/.

26 EY, Renewable energy country attractiveness index recai, 2017. 
27 State of Energy Access Report 2017, World Bank technical report, 2017.

282017 Annual report by MNRE, India Ministry of New and Renewable (MNRE) technical report, 2017.

29 Renewable Energy Prospects for India, International Renewable Energy Agency (IRENA) technical report, 2017.

30 M. A. Schreurs, Theoretical Inquiries in Law, 2013, 14, 83108.

31 R. Diermann, WWF says $2 \%$ of Germany's surface is enough for 100\% renewables, 2018, https://www.pvmagazine.com/2018/10/17/wwf-says-2-of-germanyssurface-is-enough-for-100-renewables/

32 P. Denholm and R. Margolis, The regional per-capita solar electric footprint for the United States, National Renewable Energy Laboratory (NREL) Technical Report Nrel/Tp-67042463, 2007.

33 S. Ong, C. Campbell, P. Denholm, R. Margolis and G. Heath, Land-Use Requirements for Solar Power Plants in the United States, National Renewable Energy Laboratory (NREL) tech- nical report, 2013.

34 Statistics-Times, World Population Density, 2019, https: //statisticstimes.com/demographics/countries-bypopulation-density.php.

35 D. Hales, REN21 Renewables 2018 global status report, Ren21 technical report, 2018.

36 Solar - Übersicht zur Entwicklung Erneuerbarer Energien in allen Bundesländern - Föderal Erneuerbar, Agentur für Erneuerbare Energien (AEE) technical report, 2020.

37 International Energy Statistics, U.S. Energy Information Administration (EIA) technical report, 2019.

38 S. Wurster and C. Hagemann, Energy Policy, 2018, 119, 610 619.

39 M. Mele, International Journal of Energy Economics and Policy, 2019, 269-273.

40 G. Morelli and M. Mele, International Journal of Energy Economics and Policy, 2020, 443-449.

41 Photovoltaics Report, Fraunhofer Institute for Solar Energy Systems (ISE) technical report, 2020. 


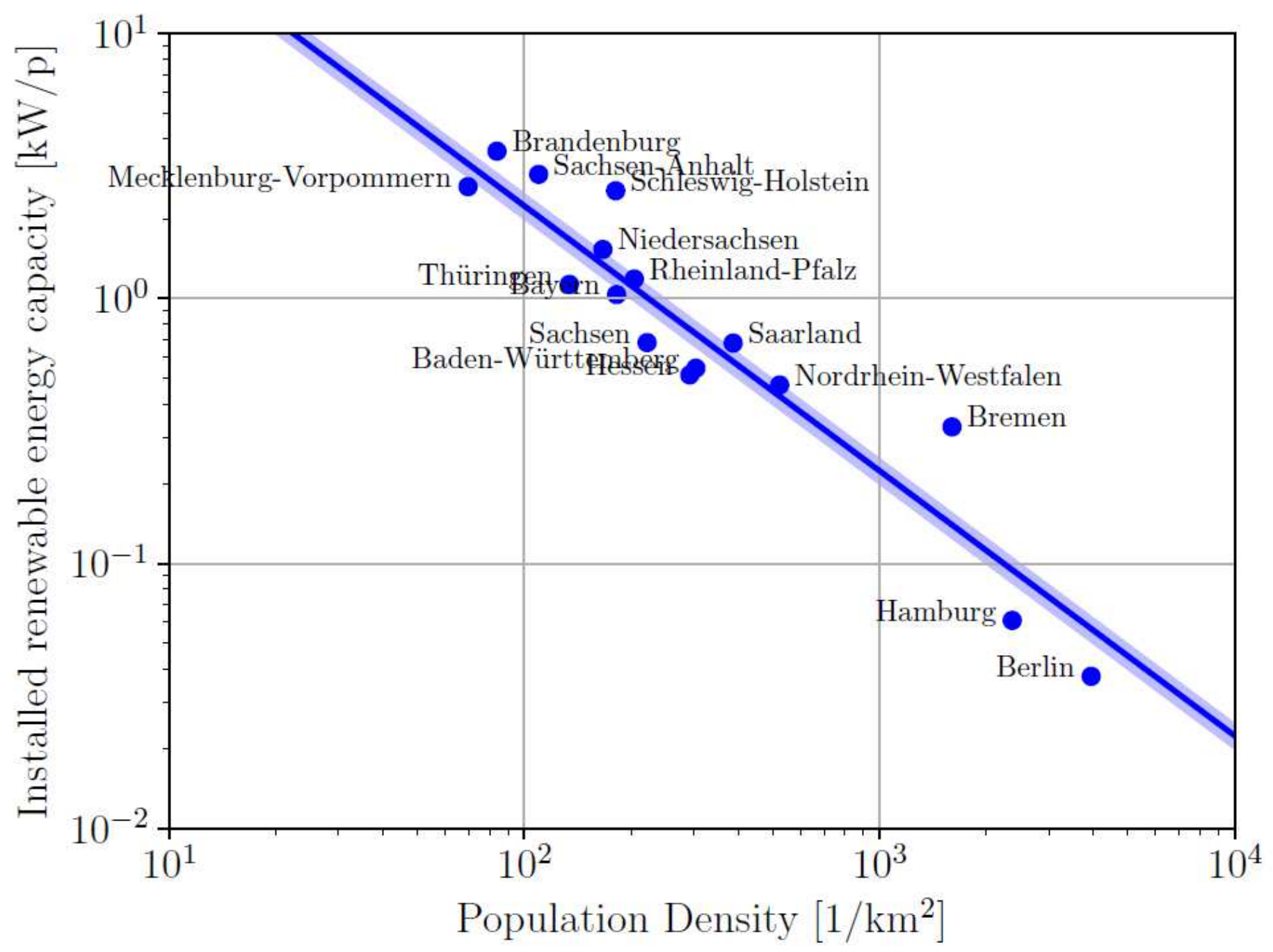

\section{Figure 1}

Installed VRE capacity per capita vs the population density, in the di' erent German states (2015). The blue line results from (3) with the best estimate for $b$, the light blue band stands for an error of \pm standard deviation in b. Data source: Germany Renewable Energies Agency. 


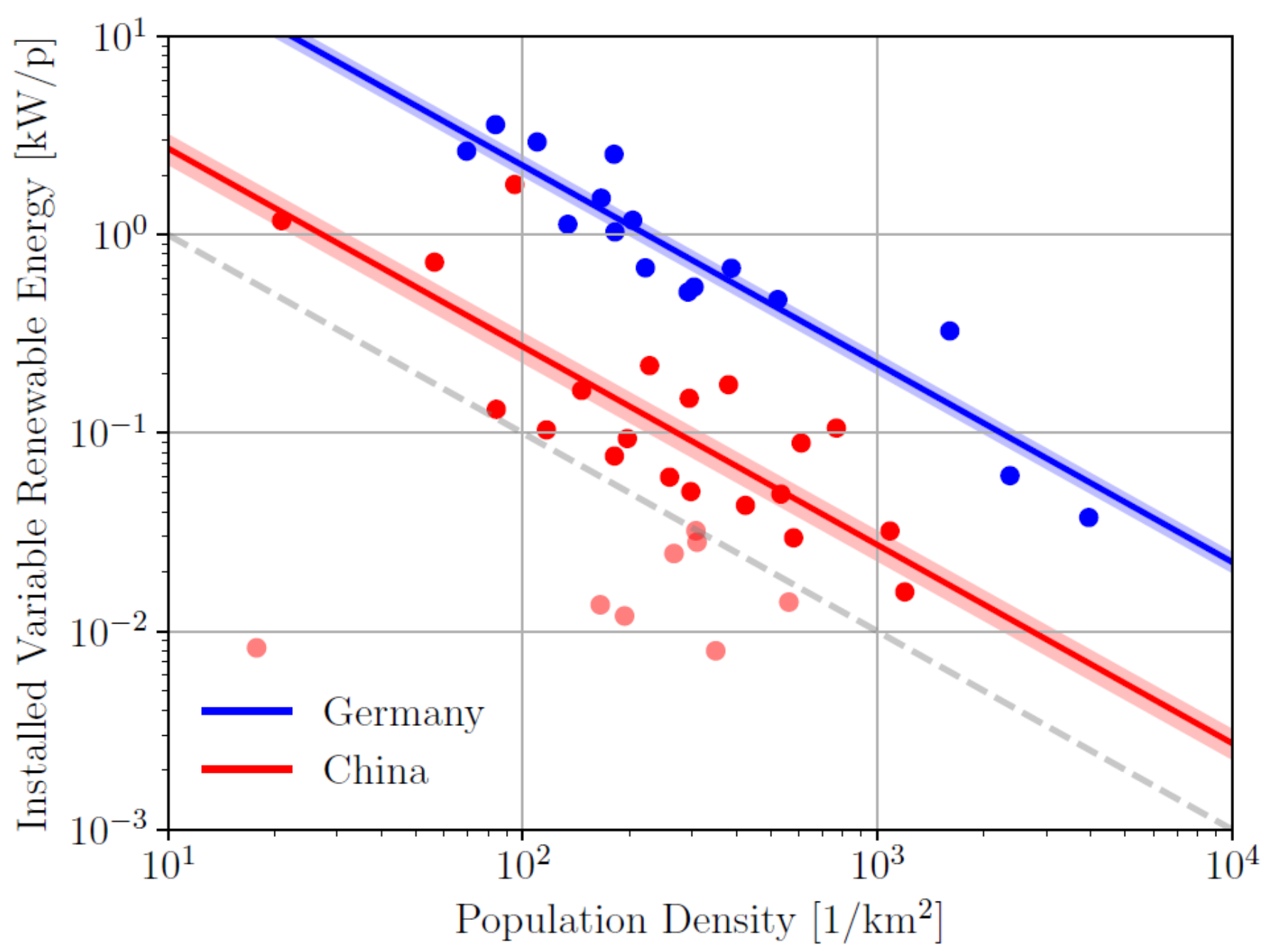

Figure 2

Germany and China states Installed VRE capacity per capita vs the population density (2015). The blue dots are Germany's states and the blue line shows Germany's $0.23 \pm 0.02 \mathrm{~W} / \mathrm{m} 02027 \mathrm{fit}$. OThe004red dots2 are China's states and the red line shows China's . \pm . W/m gradient. The light gray band stands for the cuto of $0.001 \mathrm{~W} / \mathrm{m} 2$ for states with low power density. 

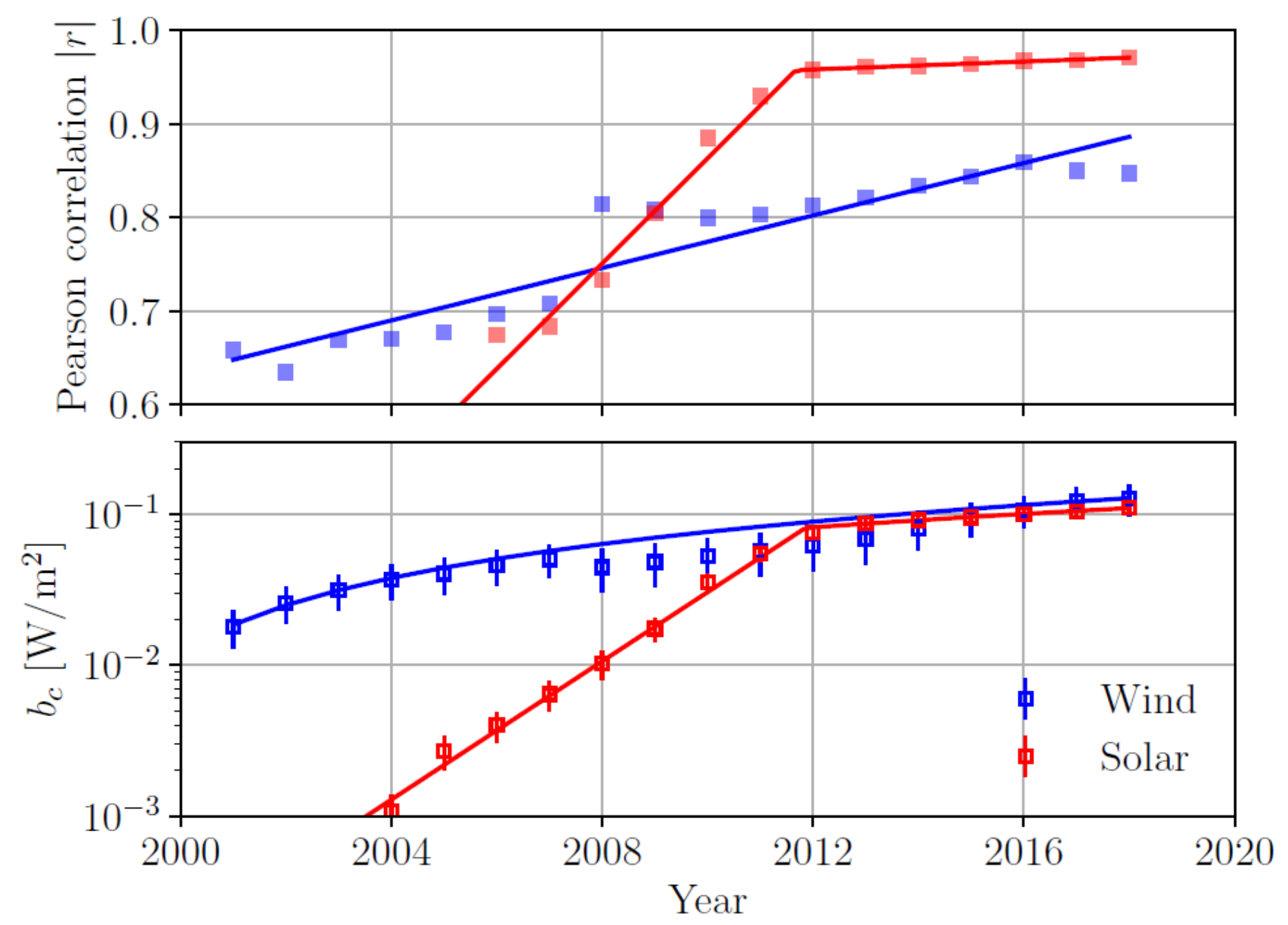

Figure 3

The correlation between installed VRE capacity per capita and the population density in Germany as a function of time. Top: The absolute value of the Pearson correlation jrj. Bottom: The power density parameter bc. Blue squares: onshore wind. Red squares: solar. The lines are linear or exponential fits to the data. 


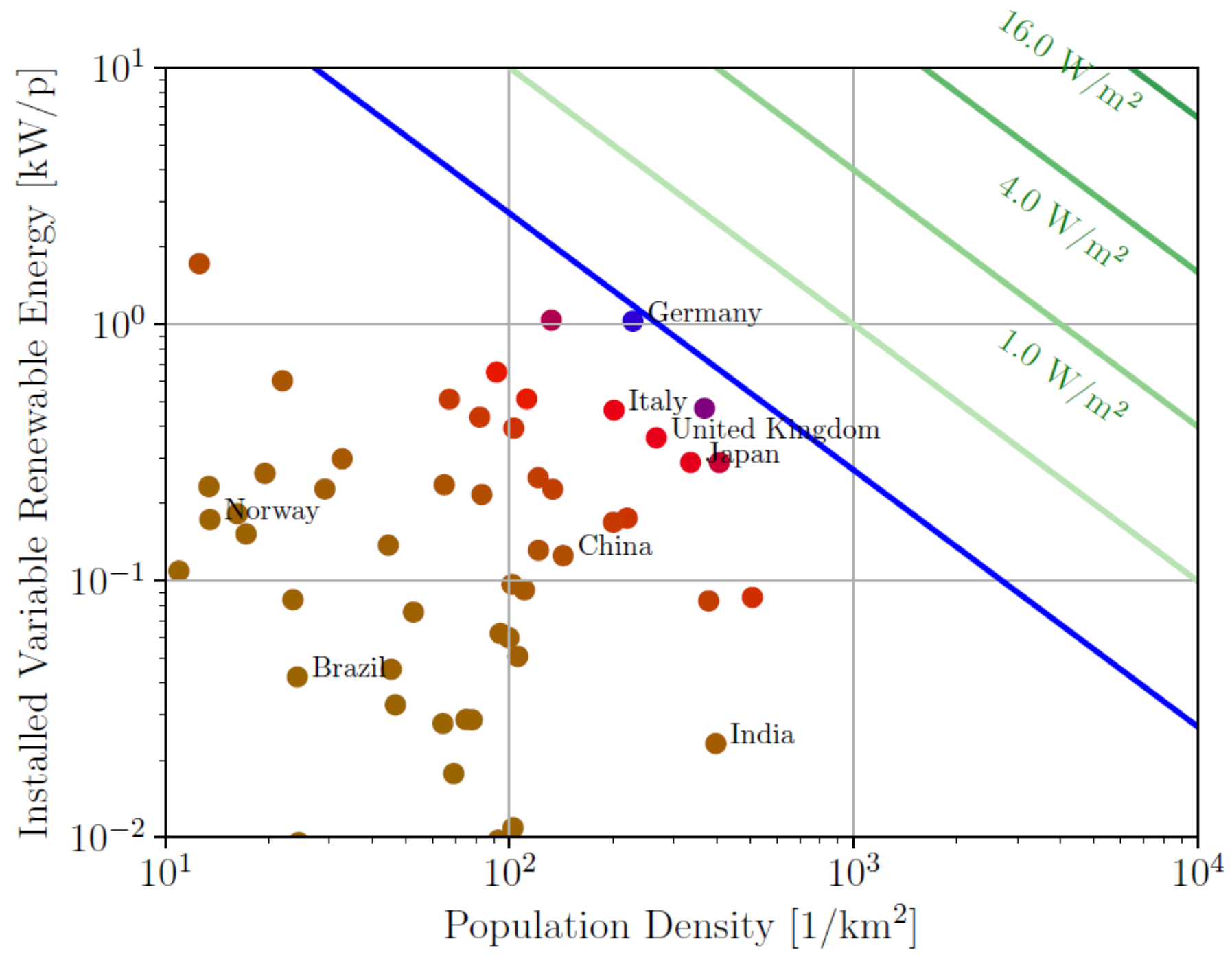

Figure 4

Installed VRE and population density for 131 countries worldwide (2015 data). 35 The blue trend line represents Germany's (2018) $0.27 \mathrm{~W} / \mathrm{m} 2$ fit. The green lines represent theoretical solar and wind density calculated theoretical limits of $1.0,4.0,16.0 \mathrm{~W} / \mathrm{m} 2$. 


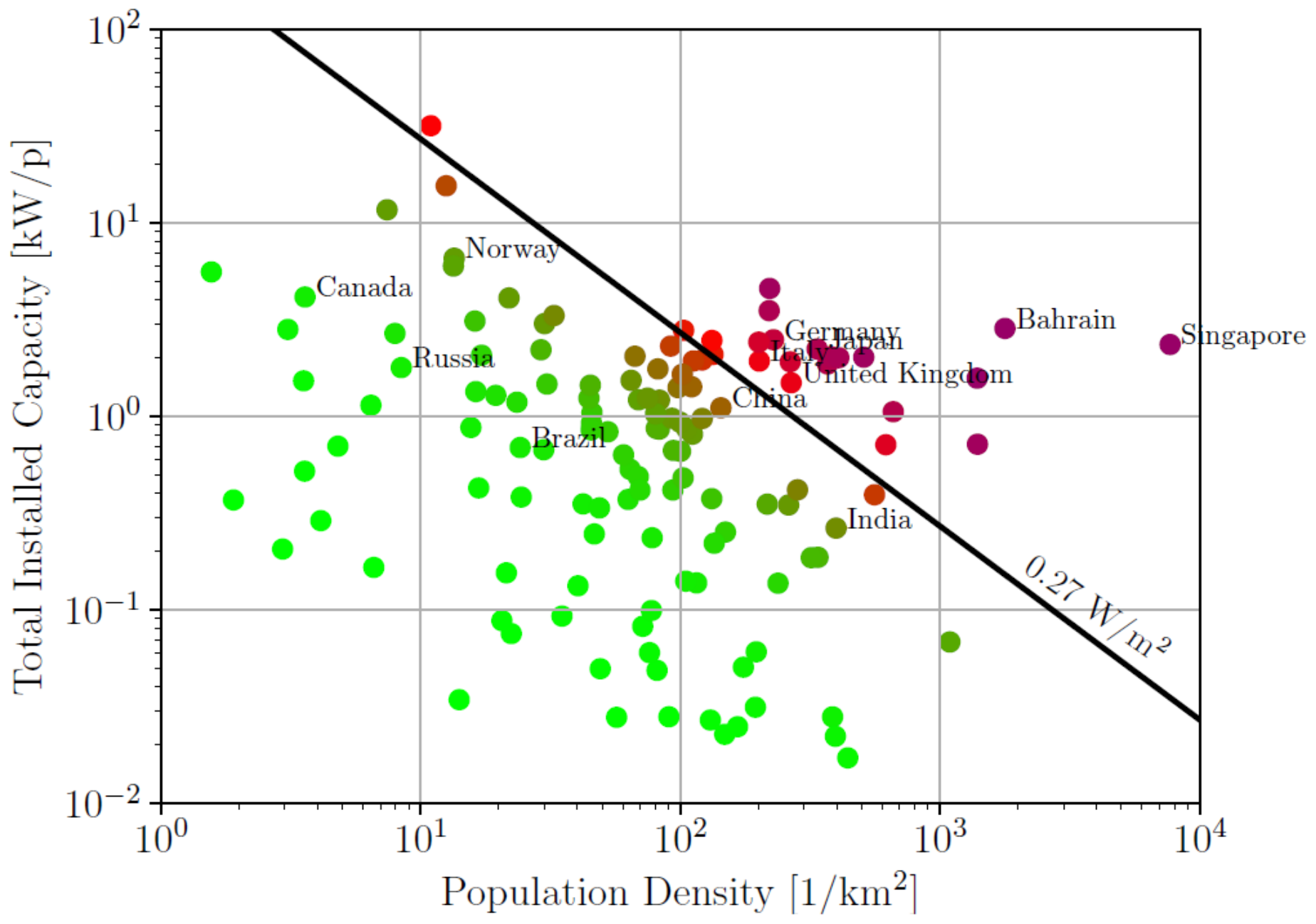

Figure 5

The installed electricity production capacity and population density for 131 countries worldwide (2015 data). The black trend line rep-resents Germany's 2018 bc $=0.27 \mathrm{~W} / \mathrm{m} 2$ value. 